\title{
PSICOLOGÍA
}

\section{Violencia intrafamiliar: percepción, conocimientos y creencias en futuros trabajadores de salud mental}

\author{
María del Pilar Frescoํㄹ Carmen Marina Arrom Suhurt², María \\ Auxiliadora Arrom de Orrego ${ }^{2}$, Marcos Hernán Capurro ${ }^{1}$, \\ Cristina Arrom Suhurt ${ }^{1}$
}

\section{Resumen}

Introducción: La violencia no es un fenómeno exclusivo de esta época ya que se ha manifestado y ha permeado la historia de la humanidad. Guerras, la tortura, los crímenes, la persecución ideológica y religiosa, los castigos domésticos, la disciplina represiva en las escuelas, instituciones y en las familias, han sido fenómenos presentes en todas las épocas. Estructurada sobre el ejercicio abusivo del poder, la violencia puede presentarse en múltiples modalidades y en ocasiones, generar consecuencias difíciles de medir de manera inmediata y a largo plazo. Según la OMS (2014), a pesar de que se trata de un "delito oculto", las razones que convierten a la violencia contra las mujeres en un tema prioritario para los/as profesionales de la salud, son, en primer lugar, que aproximadamente una quinta parte de la población mundial femenina padece de violencia y sus consecuencias negativas; en segundo lugar, que cada vez aumentan más los estudios que muestran el impacto negativo en la salud (maternidad y planificación familiar, enfermedades crónicas, físicas y mentales) y por último que los/as profesionales de la salud constituyen el principal punto de apoyo para muchas de sus víctimas. Debido a la cantidad de víctimas, es insoslayable plantearse en Paraguay las siguientes interrogantes: ¿Cómo se encuentran los servicios que reciben a las víctimas cuando van a solicitar ayuda? ¿Quiénes son los profesionales que reciben estas personas? ¿Cuál es la formación profesional respecto al abordaje de la violencia institucional, individual y de género? Centrar los estudios sobre violencia en las percepciones, actitudes y creencias culturales que contribuyen a sostenerla, constituye una forma eficaz y sólida de construir bases para eliminarla como práctica cultural y prevenir su incidencia.

Objetivo: Analizar los conocimientos, actitudes y creencias sobre violencia en estudiantes universitarios/as de Psicología en la ciudad de Asunción y Central, Octubre de 2015.

\footnotetext{
1. Cátedra de Psiquiatría, Facultad de Ciencias Médicas, Universidad Nacional de Asunción, Paraguay.

2. Centro para el Desarrollo de la Investigación Científica (CEDIC), Paraguay.

E-mail: pilifresco@gmail.com
}

DOI: 10.26885/rcei.foro.2017.127 
Material y Método: Estudio descriptivo diagnóstico de corte transverso y de carácter cuantitativo. La muestra de estudio estuvo compuesta por estudiantes universitarios/as del 1ro al 5to Curso de la Carrera de Psicología en las universidades de Columbia y Universidad Iberoamericana (sede Asunción y San Lorenzo) en el año 2015. Se tomó el 100 \% de la población de 18 a 30 años que asistieron en el día seleccionado para aplicar la encuesta de violencia y prestaron su colaboración. La muestra fue de 146 estudiantes. Se aplicó un cuestionario auto administrado, estructurado y anónimo, con preguntas cerradas y abiertas conteniendo todas las variables a ser observadas. Variables sociodemográficas; Para creencias de violación: escala de Mitos de violación del estudio de Saldívar Hernández (2004); Mitos de violación en el hombre y Mitos de violación en la Mujer. Y para conocimientos sobre violencia se pasó un listado de diez resultados de investigaciones recientes sobre el estado del arte en Violencia Doméstica aplicando frases de falsos y verdaderos. Hoja de cálculo Excel y el paquete estadístico SPSS versión 15.0 para Windows 7, e incluyó estadística descriptiva y analítica; Para el análisis se obtuvo primeramente la frecuencia de todas las variables, y se realizó la prueba de chi cuadrado a un nivel de significancia de 0,05. También se realizó el alfa de crombach para establecer la coherencia interna de los datos obtenidos. Se respetó la confidencialidad de la información asignando códigos a las encuestas. La participación fue voluntaria; Se proporcionó información suficiente y clara sobre el estudio y se administró un consentimiento informado.

Resultados: La mayoría, 61,6\% (90) se concentraba en el rango de 18 a 25 años, $82,9 \%$ (121) pertenececían al sexo femenino. Se encontraban soltero/as 73,3\% Respecto al año académico se halla en primer curso de la carrera el 30,8\% (45), en el segundo curso $19,9 \%$ (29) En tercer curso 16,4\% (24), en cuarto curso 18,5 (27), en quinto curso $10,3 \%(15), 3,4 \%$ (5) sexto curso y no respondió $0,7 \%$ (1) Se encuentran viviendo dentro de una familia nuclear de origen 44,5\% (65) $22,6 \%$ (33) vivía con su familia actual (pareja e hijos propios); $12,3 \%$ (18) en una familia monoparental; 9,6\% (14) en una extendida; $1,4 \%$ (2) con sus hermanos; $3,5 \%$ (5) solo y $0,7 \%$ (1) con el novio y 5,5\% (8) no respondió. Respecto a los conocimientos sobre el estado del arte de la violencia, gran parte de la población tenía conocimientos ciertos respecto a la realidad del mapa de prevalencia y de las formas de violencia, aunque una gran parte del grupo, también mostró desconocimiento y conocimientos falsos sobre la violencia de género. En los mitos de violación del hombre, fue donde mayor número de creencias de legitimación de violencia se encontró, principalmente la idea de que Los hombres que sufrieron un ataque o violación en cierto modo son culpables por no ser cuidadosos, ya que casi la totalidad de la población lo sostuvo. En los mitos sobre violación en la mujer se encontró que dos tercios de la población no tenían creencias que legitiman la violación en mujeres, a diferencia del hallazgo en los mitos de violación del varón, aunque se encontró sistemáticamente un porcentaje de la población que mantenía creencias legitimadoras. 
Conclusiones: La violencia nunca puede ser justificada por razones disciplinarias o tradiciones culturales, tampoco se pueden aceptar niveles "razonables" de violencia por el peligro de una violencia legalizada que llevará indefectiblemente a la tolerancia de la violencia en general. Asegurar que en la currícula de las facultades con profesiones sanitarias se incorporen los contenidos dirigidos a la capacitación para la detección precoz, intervención y apoyo a las víctimas de la violencia de género. para mejorar tanto la detección como el posterior seguimiento y/o tratamiento que los/as profesionales de la salud dan a la violencia contra las mujeres en la pareja, se debe mejorar su formación en la materia. El presente constituye un primer estudio en el país sobre un tema muy actual, poco explorado en Latinoamérica, que tiene la limitación de estudios con muestreo no probabilístico. Por lo cual, requiere ser considerado como una primera aproximación al tema, que requiere de mayor profundización.

Palabras clave: violencia doméstica, conocimientos creencias, estudiantes de psicología.

\section{RefERENCIAS}

Arrom, C. (2015). Violencia doméstica: una pandemia resistente. Mem. Inst. Investig. Cienc. Salud, 13(3), 3-4 .

Gómez, A. (1996). Por el derecho a vivir sin violencia: acciones y propuestas desde las mujeres. Cuadernos Mujer Salud, 1.

Hernández, G., Lira. L. \& Méndez, M. (2015). La aceptación de la violencia y los mitos de violación en estudiantes universitarios: Diferencias por sexo, edad y carrera. Revista de la Facultad de Medicina de la UNAM, 50(2), 71-75.

Hernández, G., Lira. L. \& Méndez, M. (2004). Validación de las escalas de aceptación de la violencia y de los mitos de violación en estudiantes universitarios. = Validation of the violence acceptance scale and rape myths in university students. Salud Mental, 27(6),40-49.

Martínez González, M., Robles Haydar, C., Utria Utria. L. (2014). Amar Amar. J. Psicología desde el Caribe, 31(1), 133-160.

OPS/OMS. (2015). Violencia contra las mujeres y contra los niños y las niñas: Areas claves de la OPS/OMS para la acción. Recuperado de http://www.paho. org/hq/index.php?option=com_content\&view=article\&id=9

Villafañe Santiago, Á., Jiménez Chafey, M., Carrasquillo, J. \& Vázquez Ramos R. Construcción y validación del cuestionario de experiencias de violencia en las relaciones de pareja y familia en estudiantes universitarios. Universitas Psychologica, 11(1), 207-215. Available from: PsycINFO. 